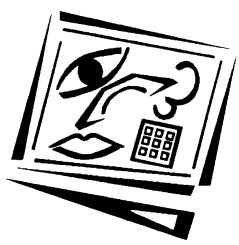

\title{
Changing relationship: Who is the learner and who is the teacher in the online educational landscape?
}

\author{
Dorit Maor \\ Murdoch University
}

\begin{abstract}
This article focuses on the special role of students as discussion leaders and their engagement in the facilitation of online discussion in relation to the teacher's role. The methodology combined quantitative data of students' frequency behaviour with qualitative analysis of students' individual online contributions. Each contribution was analysed in relation to one of the six facilitation roles plus the direct instruction category. In the seven that were used to compare the discussion leader's role with the teacher's role, the discussion leaders performed higher than the teacher in the following: summing up and confirming, moving the discussion forward, focusing the discussion and debriefing. The teacher demonstrated more frequent behaviours in the following: direct instruction and encouraging and giving feedback. Scaffolding had a similar frequency for the discussion leader and the teacher with a slightly higher rate. The task given to each member to be a discussion leader enabled new relationships between the teacher and the learners and new relationships among the learners, with everyone being empowered, changing their learning experiences and promoting the learning of others in the community.
\end{abstract}

\section{Introduction}

In recent research (Maor, 2007) I focused on the nature of online interactions and identified the type of interactions as social and cognitive processes. Against a newly constructed framework (Penman \& Lai 2003; Hendricks \& Maor, 2004; Heckman \& Annabi, 2005) using social and cognitive processes of online interactions, analysis was conducted to establish the social and cognitive attributes of online interactions using performance profiles (Aviv, 2000). After establishing this understanding, the next research phase evolved into examining the contribution of the various participants to the development of the cognitive interactions. This inquiry required a different set of codes for the analysis of categories of interaction. Aviv (2000) suggests that this type of interdependency between learners in the community results in "promotive interaction". He describes these as actions of individuals that substitute for each other. These are also when "participants positively invest energy to support each other's actions and there is a high degree of openness among participants" (p. 55).

This research utilises the same set of data as mentioned above (Maor, 2007) to understand the role of the student as discussion leader, and whether the discussion leader can replace a teacher in managing the discussion. This question was raised in previous studies of online learning (Johnson, Bishop, Holt, Stirling \& Zane, 2001; Aviv, 2000). Although the first analysis reveals that cognitive and social processes are mutually interactive and overlapping in online learning, it is important to know who contributes to the facilitation of the cognitive learning and in what ways. This is the focus of the current paper. 
In an attempt to transform information into knowledge in online teaching, greater emphasis needs to be placed on examining the nature and content of cognitive interactions (Heckman \& Annabi, 2005; Penman \& Lai 2003; Maor, 2007). One learner suggested that "the contribution of the community members to create good, interactive community of learners" held the community together, but at the same time another student pointed out that the "academic exchanges" held the community together (Maor, 2007). Either way, the intensive use of online discussion enables an analysis of the interactions and their content to answer the research questions.

\section{Literature review}

Over the last decade the number of web based, or online or 'cyberspace' courses has rapidly increased and many universities provide online graduate courses (Lee \& Nguyen, 2007). Online teaching has created innovative and effective ways of teacherstudent and student-student interactions, which rely on the increasing use of new technologies. It brought flexibility and convenience and greater opportunities to create online learning communities of practice (Aviv, 2000; Garrison, Anderson \& Archer, 2000; Reeves, 2005). However, it did not necessarily correlate with higher levels of academic achievement (Lee, Carter-Wells, Glaeser, Ivers \& Street, 2006). Nevertheless, a positive correlation was found between a sense of community and perceived learning engagement, perceived learning and student satisfaction (Liu, Magjuka, Bonk $\&$ Lee, 2007). Active interaction was also a significant predictor of perceived learning (Rovai \& Barnum, 2003).

Research further suggests that to have meaningful learning the members of the community have to be socially connected and feel confident about the learning environment and trusting of other learners before achieving any cognitive gain (Conrad, 2005; Maor, 2003; Rovai, 2002). According to Brown (2001), when students perceive a close connection to an online learning community, they often place a higher priority on learning and spend more time devoted to it. This in return may result in more productive learning communities, which according to many researchers are essential for successful learning environments (Palloff \& Pratt, 1999; Squire \& Johnson, 2000; Wenger, 1998). Communication and collaboration between the members of the community required adoption of personal responsibility and shared control while relying on fellow students for interpretation (Cleveland-Innes, Garrison \& Kinsel, 2007).

The use of online discussion as an integral part of the online teaching is underpinned by a social constructivist approach to teaching and learning and in particular by the guided opportunities for interaction to co-construct knowledge (Carabajal, LaPointe \& Gunawardena, 2003; Maor, 2003). Peer learning is part of the social fabric of the community and gives an opportunity for students to bring their variety of preexperiential knowledge to the discussion and promotes dialogue and learning (Hendriks \& Maor, 2003). In these interactions the members of successful online learning communities, according to Twigg (2001), often take on the role of the teacher more often than do students in traditional classrooms. Other studies (Johnson, 2001; Rogers, 2003) suggest that students from online communities tend to learn more from information added by their peers than from the teacher.

In Maor's study (2003), the role of facilitator was extended to include members of the community on a rotation basis to let them experience the responsibility of the teacher 
by presenting the weekly topic, posing relevant questions and providing a synthesis of the discussion (Maor, 2003). According to Ikpeze (2007), involving group members in rotational leadership style also helped them become a more cohesive team and each person's individual contribution was accounted for. Heckman \& Annabi (2006) see the role of the teacher as "developing thoughtful and stimulating questions and raising issues that generate active participation" (p. 143). These studies suggest that students experience intellectual and leadership responsibilities while acting in the role of facilitator. Wallace (2003) advocates that, while members of the community help each other to make sense of information and ideas, the teacher should have a further responsibility to act as a mediator to focus and guide the discussion. In the current study the teacher examines the interaction to assess learning progress based on each student's online contributions to the community knowledge construction, and also analyses the discussion leader's ability to engage in question based facilitation and, to a lesser extent, content based presentations.

\section{Methodology}

The course used for this research was a postgraduate unit on e-learning in a school of education, conducted exclusively online involving asynchronous discussion with an average of 12 participants per cohort. The asynchronous discussions used the same format: background readings with focused questions posted by the facilitator and students had the role of the discussion leader once or twice during a semester. The role of discussion leader was defined and demonstrated to the students. They were asked to lead and promote the discussion, add relevant questions and material, synthesise learners' contributions and summarise at the end of the topic. The unit was underpinned by social constructivist pedagogy and therefore included a strong emphasis on students engaging in interaction and dialogue (Maor, 2003). The instructor and students relied on these asynchronous forums to engage one another in ways that replaced face to face communication (Marra, 2006). About two thousand 'postings' were analysed from 2004 to 2006. These were then placed in the categories as noted in Figure 1 and the percentage of interaction was calculated for the teacher and discussion leaders.

To answer the research question, "what is the role of the student as discussion leader and can the discussion leader replace a teacher in managing the discussion", it is important to examine "what roles discussion leaders perform?" Therefore a further framework based on the work of Heckman and Annabi (2005) was employed. This framework focused on the teaching process out of the four of social process, cognitive process, teaching process and discourse process. The teaching process involved direct instruction and facilitation. This also allowed the coding of 'interactions' for the discussion leaders and for the teacher, against the roles of direct instruction or facilitating (Figure 1). The different categories of interactions (student-student, student-group, student-teacher and student-discussion leader) were condensed into two main groups: all student-student interactions and all teacher-student interactions.

A number of models for teacher's roles exists (Anderson, Rourke, Garrison \& Archer, 2001). The selected model of facilitation (Figure 1) reflects the roles that the teacher and the discussion leader demonstrated in the current study. It also examines the extent to which the communication and interaction between the students and the teacher were active interactions (Palloff \& Pratt, 1999) and exhibited collaborative learning (Harasim, 2000). The teaching process is described as giving direct instruction or 
facilitating. Facilitation was then coded to reflect a variety of forms: focusing the discussion, summing up and confirming, encouraging and giving feedback, scaffolding, moving the discussion forward and debriefing.



Figure 1: Types of interaction and facilitation

Qualitative content analysis enabled me to examine in more detail the specific categories of cognitive attributes, and compare the sub-categories in relation to the discussion leader's role. The number of interactions in each interactive category provided the quantitative dimension and enabled a comparison between the two types of interactions. Excerpts from the original online interaction are used to support and further demonstrate the nature of cognitive learning that took place during a semester of three consecutive cohorts. The data were generated from an exclusively online asynchronous discussion of university cohorts in three consecutive years. Nvivo, a software program for qualitative analysis (QSR, 2007), was used to categorise the interactions among the students and the teacher.

\section{Results}

To answer the research question of what roles do discussion leaders perform and whether a discussion leader replace a teacher in managing the discussion, I coded the interactions for the discussion leader and for the teacher, against the role of direct instruction and facilitation. Figure 2 helps us to understand the role of the discussion leader by illustrating the differences between the discussion leader's facilitation actions and the teacher's facilitation actions during five selected topics and from 1157 postings from the online course. 


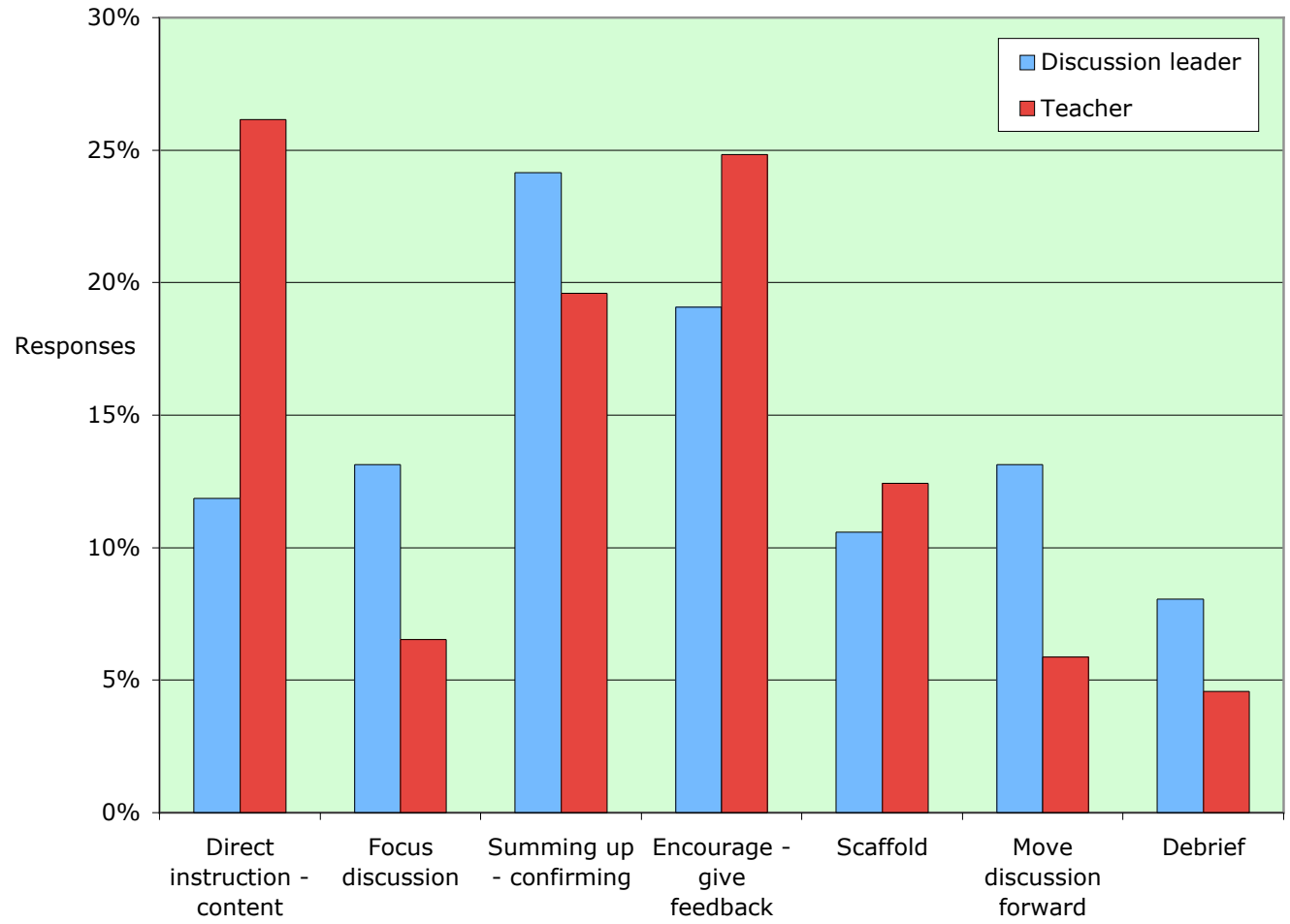

Figure 2: Discussion leader and teacher facilitation

The analysis of the type and number of postings related to facilitation by the discussion leader and the teacher suggests that the teacher tends to give more direct instruction/content related postings and encouragement and giving feedback than the discussion leader. The direct instruction by the teacher contained $26 \%$ of the interactions compared with $12 \%$ posted by the discussion leaders during the five selected topics. Encouragement and giving feedback were $25 \%$ of the postings and were more frequently done by the teacher compared with 19\% done by the discussion leader.

However, the discussion leaders' postings were higher in four types of facilitation: summing up and confirming (24\% compared with $20 \%$ of the teacher's posting), focusing discussion (13\% compared with $7 \%$ of the teacher's postings), moving the discussion forward (13\% compared with 6\% of the teacher's postings), and debriefing (8\% compared with $5 \%$ of the teacher's postings). Scaffolding (11\% compared with $12 \%$ of the teacher's postings) came after moving the discussion forward in terms of percentages and was very close for both the discussion leaders and the teacher, with the teacher having a slightly higher percentage of postings in this category.

The following excerpts from the postings serve as examples to illustrate the facilitation action in these categories. They are presented in the order from highest to lowest percentages based on the discussion leaders' types of facilitation. Before presenting the different types of facilitation, the next section begins with the task of direct instruction/posting content, which was the highest type of interaction by the teacher. 
Direct instruction and presentation of content was implemented more frequently by the teacher and less so by the discussion leaders. For example:

This afternoon I attached a PDF of a reading by Gerald E. Hein, The Challenge of Constructivist Teaching. In it he shares his experiences teaching a Masters program consisting of students undertaking an Independent study program. (Rose, 2005)

For our discussion on OLP, we will discuss this until Thursday morning, Eastern Standard Time and then from then we will discuss the issue of BL. For the sessions on OLP, we have one reading to complete and a number of activities. (Geoff, 2006)

Please check the Power Point Presentation for week two in the lecture material, reflect on the reading but also on your colleagues' ideas and join the conversation. I expected your message once or twice during the week. My advice is always to write in a word document and then cut and paste into the WebCT discussion. (Teacher, 2004)

When students took the role of the discussion leader, they attempted to show their facilitation skills. The highest use of facilitation was in summing up and confirming. The following are examples of these facilitation skills by students who acted as discussion leaders:

This week we have grappled with philosophy, starting with Socrates and the question: What is knowledge? We briefly read of the development of views of knowledge, Behaviourism and then to the work by Von Glasersfeld who expressed the concept of knowledge as dependent on the individual and their perception... (Rose, 2005)

Plenty of definitions of community in this thread and agreement with the definitions. I too agree that a community is a group of people who is working towards achieving a common goal in this case ... (Kate, 2006)

The teacher also had a fairly high proportion of postings of the type of summing up and confirming, for example:

Some of the concepts that you used last week included: Community environment, personal touch, human factor, effective learning environment, connection, discussion....This rich list is some of the new vocabulary that you are using as a learner in this online learning environment. (Teacher, 2004)

All of you raised some important concerns in our previous postings...

Brad in his message emphasises the formative assessment as a continuous feedback which increases the learner's involvement and motivation in the learning process.

(Teacher, 2006)

Although the number of postings by discussion leaders was high from the type of encouraging and giving feedback, there were more teacher encouragement and feedback types of postings than the discussion leader feedback. For example, some of the teacher postings were:

The best part of the discussion was the level of reflection that you have all demonstrated. I don't think that if I explained or modelled the Discussion Leader's role better, your reflection ability would have been further improved and as Ryan stated, I would defeat my purpose of letting you grow into your role, and experience the process of constructivist type of learning within the community. (Teacher, 2004)

Thank you for your feedback on our unit assessment... I wanted you to be more engaged with this issue therefore I asked for your views. This posting also should 
serve as an example of summary for discussion leaders. Kate, your Weblog which is very good, created a new dilemma for me and the learning outcome for me as a course coordinator .... (Teacher, 2006)

The postings of encouragement and feedback from the discussion leaders were similar but less frequent:

Tim's response to this was particularly insightful. Is constructivism purely a technique that can be switched on/off at will? I like Tim's example of his Career Ed course and the response of his students. (Gary, 2004)

... but many of you are too critical of your own performances. You have all done well with each adding their own individuality to the role. Don't forget we are just starting along this learning continuum of constructivist teaching. (Mia, 2004)

I agree with Kate that modelling is an important factor for communities, especially online communities like ours. The community leaders have a responsibility to other members to ensure that the conditions for membership are clear and that approved behaviours are encouraged. (Brad, 2006)

The third frequent way that discussion leaders facilitated was by focusing the discussion. A number of examples can demonstrate this type of facilitation:

We have to ask ourselves which aspects of 1 to 5 above have been utilised in this course, and then we have to suggest ways in which the course could be improved. (Ryan, 2004)

Again I ask what are the characteristics of the interactions that most increased your learning? (Brad, 2006)

The teacher's focus the discussion type of facilitation was similar in nature but always contained more challenges or requests:

This was a good session; however, I would like you to integrate more of the literature in your posting and even use quotes to support your views. I also noticed some good interaction between the learners in this group. (Teacher, 2006)

The next facilitation act which was more frequently demonstrated by the discussion leader than the teacher was moving the discussion forward. The discussion leaders were sometimes more flexible and concerned about the issues discussed, whereas the teacher was concerned about keeping the conversation going on the topic and in the time allocated. The following excerpts demonstrated this issue:

We've had many excellent individual contributions, with people sharing their piece of the jigsaw. Now it's time to fit it all together. (Ryan, 2004)

Based on our understanding of different teaching methods and the examples that we've read of in this unit, what teaching approaches would you like to implement in your own teaching situation? (Susan, 2005)

The teacher on the other hand suggested:

Be sure to read this week's reading: SOCIAL CONSTRCUTIVISM AND E-

LEARNING. There are three readings this week and you are required to answer question 2. Gerald will lead the discussion. Please support Gerald and let us keep this activity till the end of this week. (Teacher, 2006) 
The scaffolding task was similar for the discussion leaders and the teacher but was slightly more often used by the teacher. The following are first examples from the discussion leaders' facilitation followed by the teacher's example:

If you need some help in getting going this week, you might use the following questions as a starter. These questions are just a breakdown of this week's two focus questions. (Ryan, 2004)

As a starter I would like to share with you some of my thoughts. When I revisited my postings in Week 4, I was surprised by the lack of personalization of the postings. They all seem somewhat stilted. (Brad, 2006)

We have to be very mindful how we define a research study. Articles that simply described how an online course was developed is not research, even those that added a few quotes on how participants evaluated the experience is not fully research. (Teacher, 2006)

Debriefing was a facilitation task that interestingly was used less frequently by both the discussion leaders and the teacher. Nevertheless, the discussion leaders were more likely to use debriefing than the teacher:

I felt like the chat session got "warmed up" fast enough to really start some interesting discussion. I actually felt like we were having a conversation, rather than a discussion, and now I am thinking there is quite a difference between the two. (Kath, 2005)

Analysis of the interactions suggests that the discussion leaders performed highly in the facilitation areas, such as summing up and confirming the exchange of information, moving the discussion forward, helping refocus the discussion and debriefing the other learners at the beginning of the topic or at the end of a particular session. The teacher was a more active facilitator when she gave direct instructions and dealt with pedagogical content knowledge, encouraged and gave feedback. There was an almost equal number of postings for the teacher and discussion leaders that occurred in relation to the scaffolding and leading the students in the learning. Therefore, it seems that the discussion leader can replace the teacher in managing the interaction and the teacher should scaffold the students into this role. However, the data indicate that the role of the teacher is substantial in providing the pedagogical content knowledge. Thus there is a great need for the teacher to provide direct facilitation to promote higher level cognitive processes.

\section{Discussion}

The research question about the role of students as discussion leaders suggests that in some areas the discussion leader can replace the teacher in the online facilitation. Therefore, the teacher may utilise this role as a planned part of the teaching strategies that can lead to a greater learning and empowering experience for the online learners.

As early as 1992, Henri examined the quality of online postings by focusing on social, interactive, meta-cognitive and cognitive dimensions and attempted to qualitatively define the nature and content of online interactions that sustain cognitive development and meaningful learning. His analysis further developed into different studies such as Gunawardena, Lowe and Anderson (1997) who examined the quality of online learning and others who conducted discourse analysis to ascertain different aspects of online learning (Hendriks \& Maor, 2004; Marra, 2006). 
The methodology in this study combines quantitative data of students' frequency behaviour with qualitative analysis of students' individual contributions online. Each contribution was analysed in relation to one of the six facilitation roles plus direct instruction. The type of teaching strategy of peer led discussion enables the students to immerse themselves in the online experience and to learn and share ideas and frustrations with other learners. The immersion suggests that the discussion leaders immersed themselves in the community of learners and led the discussion on a rotational basis as part of the online module design. Through the immersive approach (Al-Mahmood \& McLoughlin, 2004), students gained a great deal of insight into how to transform their practice by taking a teacher's perspective through the firsthand discussion leader facilitation skills.

Heckman and Annabi (2005), in a comparison study between face to face and asynchronous learning networks (ALN) discussions, found that "student-to-student interactions in ALN contain a greater proportion of high level cognitive indicators than do student-to-teacher interaction" (p. 1). They also suggested that teacher presence is much greater in face to face discussions and that two-thirds of students' utterances online were responses to other students and were longer in ALN while teacher utterances were shorter. They also found that more than half of the instances of the teaching process in online discussion was performed by students rather than the teacher. These results inspired the current study and encouraged me to conduct a careful content analysis to answer the research question. The results from a different study conducted by Penman and Lai (2003) suggest that it is possible to achieve higher order thinking in asynchronous learning environments. They also found that the style of lecturing is important in facilitating online interaction.

In an attempt to develop the concept of community of learners, Heckman and Annabi (2006) suggested that "students are expected to consolidate their learning by teaching one another" (p. 146). In ALNs, over half of the student utterances were responses to other students. Also, they found "in the ALN discussions, virtually all instances of identifying agreement and disagreement were performed by students themselves and not by the teacher" (p. 146). These results were slightly different from the current study that found over half of the interactions occurred between the teacher and the students and to a lesser extent between the students themselves.

Not many studies have explored online teaching in a peer led online discussion (Nicholson \& Bond, 2003; Maor, 2003; Ikpeze, 2007) or the group processes in online group collaboration involving teachers in a peer led context. There are two issues related to this study: the role of the group facilitator in online small group learning; and the process and impact of peer led group discussion on students' learning. It becomes a common routine in many online courses for the facilitator to adjust the planned curriculum, to constantly contribute and seek input from students. The students, on the other hand, responded on a regular basis and started to take leadership responsibilities in the online community.

This study found that the students' discussion leader's role enabled and promoted interactions. These interactions also created a greater commitment among the community members, which sustained the discussion during the semester long course. In addition to intense interactions, the role of the discussion leader prompted empowerment and active learning, which were two goals intended in creating this unit. This also changed the role of the teacher of this unit to a co-facilitator and co- 
learner. However, it was important to have the teacher there for encouragement and feedback and direct instruction on specific points.

\section{Conclusion and recommendations}

This paper focused on the special role of the students as discussion leaders and their engagement in the facilitation of the online discussion in relation to the teacher's role. In the six categories of facilitation plus direct instruction that were used to compare the discussion leader's role with the teacher's, the discussion leaders performed higher than the teacher in the following: summing-up and confirming, moving the discussion forward, focusing the discussion and debriefing. The teacher demonstrated more frequent behaviour in the following: direct instruction, encouraging and giving feedback/content. Scaffolding had a similar frequency for the discussion leader and the teacher with only a slightly higher rate for the teacher.

Ikpeze (2007) concluded that "unless participants in online discourse are self motivated, committed and share a common group goal, the quality and quantity of the discussions may be in jeopardy" (p. 400). I can make an inference from my study that reinforces this statement, suggesting that, at least in this instance, online learning is more suitable to mature age students who are more likely to be motivated than younger, undergraduate students.

This study adds to a number of research studies on online learning by looking at records of online discussion to answer the research question of the role of discussion leaders and whether they can replace the teacher in online discussion. According to Nicholson and Bond (2003), it is possible for adult learning to obtain meaning through collaborative learning with minimal input from instructors. The role of rotational leadership, which was examined in this study, helped learners to achieve the learning outcomes of the course. Clear goals and expectations also helped to inspire the group to achieve learning outcomes and to create a community of learners.

To answer the research question of whether the discussion leader can replace the teacher, the quantitative data suggest that the discussion leaders fulfilled most of the facilitation roles and the leadership experience provided them with the opportunity to be highly interactive, reflective and understand the new relationship between the online teacher as a facilitator and the learners in the changing educational landscape. However, the qualitative data suggest that the lecturer scaffolded the learners into reflection and interaction and guided them to immerse themselves in the online experience. Occasional social or cognitive challenges could not be resolved without the intervention of the teacher. In summary, the task given to each member to be a discussion leader enabled new relationships between the teacher and the learners and new relationships among the learners, with everyone being empowered, changing their learning experiences and promoting the learning of others in the community.

\section{References}

Al-Mahmood, R. \& McLoughlin, C. (2004). Re-learning through e-learning: Changing conceptions of teaching through online experience. In Beyond the comfort zone. Proceedings ASCILITE Perth 2004. http:/ / www.ascilite.org.au/ conferences/ perth04/procs/al-mahmood.html

Anderson, T., Rourke, L., Garrison, D. R. \& Archer, W. (2001). Assessing teaching presence in a computer conferencing context. Journal of Asynchronous Learning Networks, 5(2), 1-17. http:/ / www.aln.org/publications/jaln/v5n2/pdf/v5n2_anderson.pdf 
Aviv, R. (2000). Educational performance of ALN via content analysis. Journal of Asynchronous Learning Networks, 4(2). http: / / www.aln.org/publications/jaln/v4n2/pdf/v4n2_aviv.pdf

Brown, R. (2001). The process of community building in distance learning classes. Journal of Asynchronous Learning Networks, 5(2), 18-35. http:/ / www.sloan-cwiki.org/JALN/v5n2/pdf/v5n2_brown.pdf

Carabajal, K., LaPointe, D. \& Gunawardena, C.N. (2003). Group development in online learning communities. In M. G. Moore \& W. G. Anderson (Eds.), Handbook of distance education (pp. 217-234). Mahwah, NJ: Lawrence Erlbaum.

Cleveland-Innes, M., Garrison, R. \& Kinsel, E. (2007). Role adjustment for learners in an online community of inquiry: Identifying the challenges of incoming online learners. International Journal of Web-Based Learning and Teaching Technologies, 2(1), 1-15.

Conrad, D. (2005). Building and maintaining community in cohort-based online learning. Journal of Distance Education, 20(1), 1-20.

http: / / www.jofde.ca/index.php/jde/article/viewFile/78/59

Gunawardena, C.N., Lowe, C.A. \& Anderson, T. (1997). Analysis of a global online debate and the development of an interaction analysis model for examining social construction of knowledge in computer conferencing. Journal of Educational Computing Research, 17(4), 397431.

Heckman, R. \& Annabi, H. (2005). A content analytic comparison of learning processes in online and face-to-face case study discussions. Journal of Computer-Mediated Communication, 10(2), article 7. http:/ / jcmc.indiana.edu/vol10/issue2/ heckman.html

Heckman, R. \& Annabi, H. (2006). How the teacher's role changes in on-line case study discussions. Journal of Information Systems Education, 17(2), 141-150.

Hendriks, V. \& Maor, D. (2004). Quality of students' communicative strategies delivered via computer-mediated communications. Journal of Interactive Learning Research, 15(1), 5-32.

Henri, F. (1992). Computer conferencing and content analysis. In A.R. Kaye (Ed.), Collaborative learning through computer conferencing. The Najaden papers (pp. 117-136). Berlin: SpringerVerlag.

Ikpeze, C. (2007). Small group collaboration in peer-led electronic discourse: An analysis of group dynamics and interactions involving preservice and inservice teachers. Journal of Technology and Teacher Education, 15(3), 383-407.

Johnson, E. M., Bishop, A., Holt, A., Stirling, J. \& Zane, J. (2001). Reflections in cyberspace: Web conferencing for language teacher education. Australian Journal of Educational Technology, 17(2), 169-186. http:// www.ascilite.org.au/ajet/ajet17/johnson.html

Lee, J., Carter-Wells, J., Glaeser, B., Ivers, K. \& Street, C. (2006). Facilitating the development of a learning community in an online graduate program. Quarterly Review of Distance Education, $7(1), 13-34$

Lee, Y.-F. \& Nguyen, H. (2007). Get your degree from an educational ATM: An empirical study in online education. International Journal on ELearning, 6(1), 31-40.

Liu, X., Magjuka, R., Bonk, C. \& Lee, S.-H. (2007). Does sense of community matter? An examination of participant's perceptions of building learning communities in online courses. Quarterly Review of Distance Education, 8(1), 9-24.

Maor, D. (2003). Teacher's and students' perspectives on on-line learning in a social constructivist learning environment. Technology, Pedagogy and Education, 12(2), 201-218.

Maor, D. (2007). The cognitive and social processes of how university students experience online 
learning. In ICT: Providing choices for learners and learning. Proceedings ascilite Singapore 2007. http: / / www.ascilite.org.au/conferences/singapore07/procs/maor.pdf

Marra, R. (2006). A review of research methods for assessing content of computer-mediated discussion forums. Journal of Interactive Learning Research, 17(3), 243-267.

Nicholson, S. \& Bond, N. (2003). Collaborative reflection and professional community building: An analysis of preservice teachers' use of an electronic discussion board. Journal of Technology and Teacher Education, 11(2), 259-279.

Pallof, R. \& Pratt, K. (2005). Collaborating online: Learning together in community. San Francisco: Jossey Bass.

Penman, M. \& Lai, K-W. (2003). Synchronous communication and higher-order thinking in a tertiary course in occupational therapy. Journal of Interactive Learning Research. 14(4), 387-404.

Qualitative Solutions Research (QSR) (2007). NVivo 7 [computer software]. http:/ / www.qsrinternational.com/

Reeves, T. (2005). Design research: A socially responsible approach to instructional technology research in higher education. Journal of Computing in Higher Education, 16(2), 97-116.

Rogers, E. M. (2003). Diffusion of innovations (5th edition): New York: The Free Press.

Rovai, A. P. (2002). Building sense of community at a distance. International Review of Research in Open and Distance Learning, 3(1).

http: / / www.irrodl.org/index.php/irrodl/article/viewFile/79/153

Rovai, A. P. \& Barnum, K. T. (2003). On-line course effectiveness: An analysis of student interaction and perceptions of learning. Journal of Distance Education, 18(1), 57-73. http: / / cade.athabascau.ca/vol18.1/ rovai.pdf

Squire, K. \& Johnson, C. (2000). Supporting distributed communities of practice with interactive television. Educational Technology Research and Development, 48(1), 23-43.

Twigg, C. (2001). Innovations in online learning: Moving beyond no significant difference. Troy, NY: National Center for Academic Transformation. http: / / www.center.rpi.edu/Monographs/Innovations.html

Wallace, R. M. (2003). Online learning in higher education: A review of research on interactions among teachers and students. Education, Communication $\mathcal{E}$ Information, 3(2), 241-280.

Wenger, E. (1998). Communities of practice: Learning, meaning and identity. Cambridge, UK: Cambridge University Press.

Dr Dorit Maor, Senior Lecturer in Tertiary and Adult Education School of Education, Murdoch University South Street, Murdoch WA 6150, Australia

Email: d.maor@murdoch.edu.au

Web: http:/ / www.education.murdoch.edu.au/staff/dorit_maor.html 